\title{
Ammonia-dependent synthesis and metabolic channelling of carbamoyl phosphate in the hyperthermophilic archaeon Pyrococcus furiosus
}

\author{
Christianne Legrain, ${ }^{1}$ Marc Demarez, ${ }^{1}$ Nicolas Glansdorff ${ }^{1,2,3}$ and \\ André Piérard ${ }^{1,4}$
}

Author for correspondence: André Piérard. Tel: +32 2 5267276. Fax: +32 2 5267273. e-mail: ceriair@ulb.ac.be

1,2 Research Institute, CERIACOOVI 1 and Laboratorium voor Erfelijkheidsleer en Microbiologie2, Vrije Universiteit Brussel, Brussels, Belgium

3,4 Vlaams Interuniversitair Instituut voor Biotechnologie ${ }^{3}$ and Laboratoire de Microbiologie 4 , Université Libre de Bruxelles, 1, avenue Emile Gryson, B1070 Brussels, Belgium

\begin{abstract}
The biosynthesis of carbamoyl phosphate (CP), a metabolic precursor of arginine and the pyrimidines was investigated in the hyperthermophilic archaeon Pyrococcus furiosus. The half-life of CP was found to be less than $2 \mathrm{~s}$ in the optimum temperature range of this organism (100-102 $\left.{ }^{\circ} \mathrm{C}\right)$. The carbamoyl-phosphate synthase (CPSase) of $P$. furiosus uses ammonia as the nitrogen donor, and not glutamine like all micro-organisms investigated so far. The $M_{r}$ of the enzyme, which is devoid of regulatory properties, is 70000 , at variance with that of known CPSases. The possible significance of these findings with regard to hyperthermophilic nitrogen metabolism is discussed. Competition experiments with $P$. furiosus crude extracts indicated a marked preference of ornithine carbamoyltransferase (OTCase) for CP synthesized by CPSase rather than for $\mathrm{CP}$ added to the reaction mixture. In addition, the bisubstrate analogue $\delta$-N-phosphonoacetyl-L-ornithine inhibits the formation of citrulline from bicarbonate, ammonia, ATP and ornithine much less than its synthesis from ornithine and $\mathrm{CP}$ in the presence of free OTCase. Such results suggest that, in vivo, CPSase and OTCase associate in a complex able to channel CP. Such a channelling may confer protection to CP, thus avoiding the accumulation of toxic amounts of cyanate arising from its decomposition as well as the waste of the two molecules of ATP required for its synthesis.
\end{abstract}

Keywords: Pyrococcus furiosus, ammonia-dependent carbamoyl-phosphate synthase, thermal lability of carbamoyl phosphate, metabolic channelling

\section{INTRODUCTION}

Carbamoyl phosphate (CP) is an essential metabolite for both arginine and pyrimidine biosynthetic pathways; ornithine carbamoyltransferase (OTCase) catalyses the formation of citrulline from ornithine and $\mathrm{CP}$ in the sixth step of arginine biosynthesis, whereas aspartate carbamoyltransferase (ATCase) promotes the condensation of aspartate and $\mathrm{CP}$ into carbamoyl aspartate in the first committed step of pyrimidine biosynthesis. CP is synthesized in vivo by a carbamoyl-phosphate synthase (CPSase) which requires bicarbonate, glutamine or ammonia, and $\mathrm{MgATP}$ as substrates (Fig. 1).

Abbreviations: ATCase, aspartate carbamoyltransferase; CP, carbamoyl phosphate; CPSase, carbamoyl-phosphate synthase; OTCase, ornithine carbamoyltransferase; PALO, $\delta$-N-phosphonoacetyl-L-ornithine.
At least three different types of CPSases have been identified on the basis of their specificity for either ammonia or glutamine as the physiological nitrogen donor, and of their requirement for $N$-acetyl-L-glutamate as cofactor. CPSase I, which requires $N$-acetyl-L-glutamate for maximal activity and does not utilize glutamine in place of ammonia, is found in liver mitochondria and functions in the urea cycle. This enzyme comprises a single polypeptide chain $\left(M_{\mathrm{r}} 155000-165000\right)$, which exists either as a dimer or in a monomer-homodimer equilibrium (Elliot \& Tipton, 1973; Lusty, 1978; Mori \& Cohen, 1978). In contrast to the latter enzyme, CPSase II uses glutamine as the physiologically significant nitrogen donor (Hager \& Jones, 1967; Jones, 1980). A first type of CPSase II is present in prokaryotes and simple eukaryotes. These enzymes are dimers comprising a small $\left(M_{\mathrm{r}} 42000\right)$ and a large $\left(M_{\mathrm{r}} 120000\right)$ subunit. The small subunit catalyses 


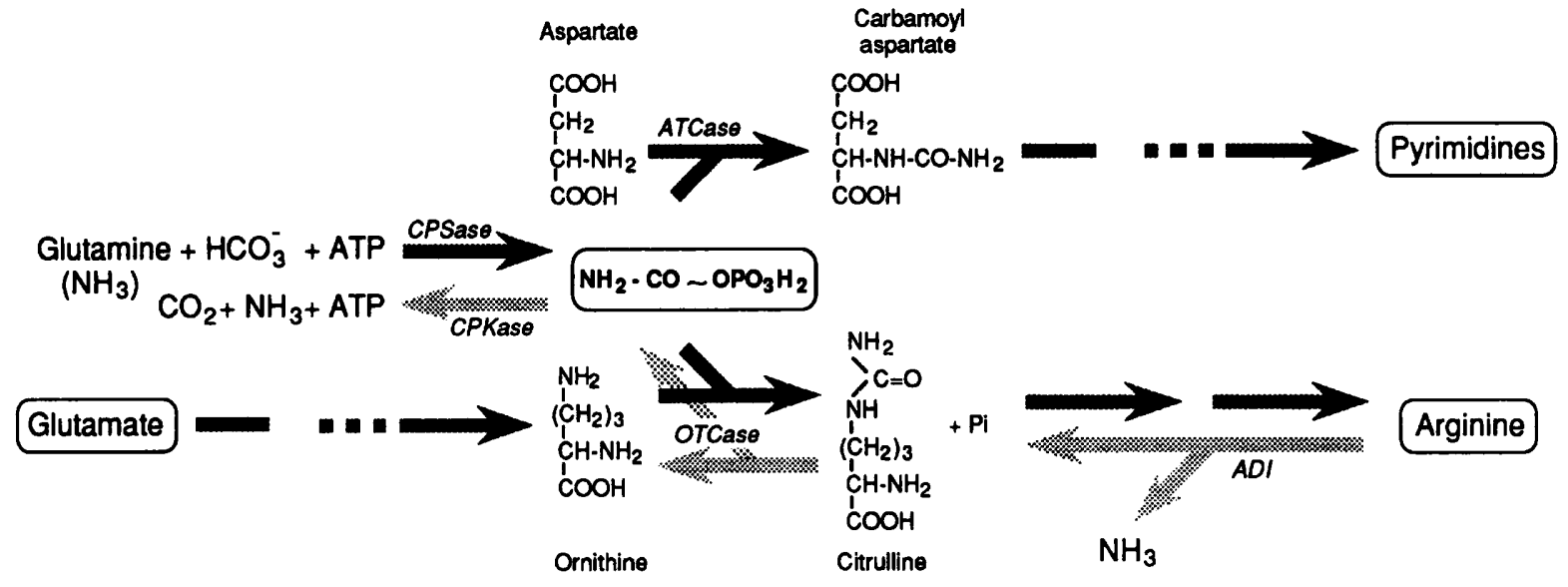

Fig. 1. Metabolic pathways involving CP. ADI, arginine deiminase; CPKase, carbamate kinase. Dark arrows, biosynthetic pathways; light arrows, catabolic pathway.

the hydrolysis of glutamine, releasing $\mathrm{NH}_{3}$ which is transferred to the large subunit; the latter subunit catalyses the formation of $\mathrm{CP}$ in a complex reaction which also requires bicarbonate ions, and two $\mathrm{MgATP}$ (Meister, 1989). Examples of enzymes in this group include the single CPSase found in enteric bacteria and the argininespecific CPSases of yeast and Neurospora (reviewed by Cunin et al., 1986; Davis, 1986; Meister, 1989). A second type of CPSase II specifically catalyses CP formation required for pyrimidine biosynthesis. These enzymes, which include the CPSase II of higher eukaryotes and the pyrimidine-specific enzymes of yeast and Neurospora, are associated as multifunctional complexes with ATCase, or with both ATCase and dihydroorotase (Williams et al., 1970; Coleman et al., 1977; Jones, 1980; Belkaïd et al., 1988). CPSase III, which is present in a number of elasmobranchs and in freshwater teleosts, uses glutamine as the nitrogen substrate and requires $N$-acetyl-L-glutamate as an activator (Anderson, 1980; Anderson, 1981; Casey \& Anderson, 1983). The enzyme comprises a single polypeptide chain with a $M_{\mathrm{r}}$ of $155000-165000$ and is subject to self-association facilitated by the presence of $\mathrm{MgATP}, \mathrm{L}$-glutamine and $\mathrm{N}$-acetyl-L-glutamate (Anderson, 1981).

Studies on the decomposition of $\mathrm{CP}$ in the mesophilic temperature range $\left(25-37^{\circ} \mathrm{C}\right)$ have shown that $\mathrm{CP}$ decomposes readily in aqueous solutions according to different reactions depending on the $\mathrm{pH}$ (Allen \& Jones, 1964). Acid-catalysed hydrolysis (pH 1-5) leads to the formation of carbon dioxide, ammonia and orthophosphate, whereas a base-catalysed reaction (above $\mathrm{pH} 6$ ) yields cyanate and orthophosphate (Allen \& Jones, 1964). At high temperatures the decomposition of CP could lead to the accumulation of toxic amounts of cyanate, a powerful carbamoylating agent under such conditions. Such a decomposition could also constitute a significant energy waste for the cell since the synthesis of each CP molecule requires two ATP molecules. This led us to propose that, in extreme thermophilic and hyperthermophilic bacteria, the involvement of $\mathrm{CP}$ in the biosynthesis of arginine and the pyrimidines depends on mechanisms that protect it against thermal decomposition (Van de Casteele et al., 1990).

It has been recognized that, in many instances, enzymes belonging to the same metabolic pathway are present in multi-enzyme complexes or multifunctional proteins (for reviews see Srere, 1987; Ovádi, 1991; Mathews, 1993). Such complexes might confer a kinetic advantage to the cell by allowing the direct transfer of metabolites between consecutive enzymes, without the need for release into the bulk phase. In extreme thermophiles, the channelling of thermolabile energy-rich intermediates such as CP could conceivably diminish the energy losses resulting from thermal decomposition at high temperature.

In this work we have investigated the kinetics of $\mathrm{CP}$ decomposition at high temperatures and indeed found it to be particularly unstable in the temperature range of hyperthermophilic bacteria. We present evidence for $\mathrm{CP}$ channelling in a hyperthermophilic archaeon, Pyrococcus furiosus, and describe the unusual properties of its CPSase. Part of this work has been published in abstract form (Piérard et al., 1992).

\section{METHODS}

Bacterial strain and culture conditions. Pyrococcus furiosus Vc1 (DSM 3638) was kindly provided by Professor K. O. Stetter, Regensburg, FRG. Bacteria were grown in a complex medium based on artificial sea-water (Fiala \& Stetter, 1986) supplemented with $0.1 \%$ yeast extract and $0.5 \%$ peptone. Cells were grown at $95^{\circ} \mathrm{C}$ in a Biolafite fermenter in 151 batch runs or in a Braun Biostat $U$ fermenter in 601 batch runs, with continuous sparging with nitrogen gas at $400 \mathrm{ml} \mathrm{min}^{-1}$ to maintain anaerobic conditions and agitation at 200 r.p.m. Cells were harvested by centrifugation at the end of the exponential growth phase (about $2 \times 10^{8}$ cells $\mathrm{ml}^{-1}$ ) and washed in $3 \%$ (w/v) $\mathrm{NaCl}$.

Preparation of cell extracts. Unless otherwise specified, cells were suspended in $50 \mathrm{mM}$ potassium phosphate buffer $(\mathrm{pH} \mathrm{7.5)}$ and disrupted by sonication for $5 \mathrm{~min}$ in a Heat Systems 
ultrasonic oscillator $(100 \mathrm{~W}, 20 \mathrm{kHz})$. After sonication, the resulting suspension was centrifuged $(15 \mathrm{~min}, 20000 \mathrm{~g})$. All these operations were carried out below $10^{\circ} \mathrm{C}$. The supernatant was used for enzyme assays.

Enzyme assays. Carbamoyl-phosphate synthase (CPSase; EC 6.3.5.5) was measured using the coupled assay with OTCase at two temperatures, 60 and $90^{\circ} \mathrm{C}$. The assay at $60^{\circ} \mathrm{C}$ was performed with $E$. coli OTCase which proved to be stable at this temperature (Legrain \& Stalon, 1976). The reaction mixture contained, in a volume of $1.0 \mathrm{ml}, 100 \mathrm{mM}$ Tris $/ \mathrm{HCl}$ (pH 9.0), $10 \mathrm{mM} \mathrm{ATP.} \mathrm{Na}_{2}, 10 \mathrm{mM} \mathrm{MgCl}, 6 \mathrm{mM}$ L-ornithine, $20 \mathrm{mM}\left[{ }^{14} \mathrm{C}^{2} \mathrm{NaHCO}_{3}\left(0.2 \mu \mathrm{Ci} \mu \mathrm{mol}^{-1}\right), 200\right.$ units of partially purified OTCase from Escherichia coli, crude extract $(0.5-2.0 \mathrm{mg}$ protein) and either $20 \mathrm{mM} \mathrm{L}$-glutamine or $100 \mathrm{mM} \mathrm{NH}_{4} \mathrm{Cl}$. After $10 \mathrm{~min}$ incubation, the reaction was stopped by the addition of $1 \mathrm{ml} \mathrm{0.25} \mathrm{M}$ trichloroacetic acid. Excess $\left[{ }^{14} \mathrm{C}\right] \mathrm{NaHCO}_{3}$ was removed and $\left[{ }^{14} \mathrm{C}\right]$ citrulline determined as described by Piérard et al. (1972). Product formation was a linear function of incubation time up to $20 \mathrm{~min}$ and of protein concentration below $2 \mathrm{mg} \mathrm{ml}^{-1}$. The assay at $90^{\circ} \mathrm{C}$ was performed in the presence of $P$. furiosus OTCase, using the same reaction mixture and an incubation time of 3 min which did not cause more than $10 \%$ loss of $\left[{ }^{14} \mathrm{C}\right] \mathrm{NaHCO}_{3}$.

Carbamate kinase (EC 2.7.2.2) activity determinations were performed by measurement of the quantity of ${ }^{14} \mathrm{CO}_{2}$ formed in $2.0 \mathrm{ml}$ of a reaction mixture containing $100 \mathrm{mM}$ Tris $/ \mathrm{HCl}$ buffer (pH 8.0), $10 \mathrm{mM}$ ADP, $10 \mathrm{mM} \mathrm{MgCl}, 5 \mathrm{mM}\left[{ }^{14} \mathrm{C}\right] \mathrm{CP}$ $\left(0 \cdot 1 \mu \mathrm{Ci} \mu \mathrm{mol}^{-1}\right)$ and extract (up to $15 \mathrm{mg}$ protein). Incubation time was $10 \mathrm{~min}$ at $40^{\circ} \mathrm{C}$. Two minutes before the reaction was stopped, $20 \mu \mathrm{mol}$ ornithine and 400 units of E. coli OTCase were added to transform the $\mathrm{CP}$ which had not reacted into citrulline. ${ }^{14} \mathrm{CO}_{2}$ was measured as described by Legrain \& Stalon (1976). The non-enzymic degradation of CP was measured in control samples without extract.

OTCase (EC 2.1.3.3) was assayed by measuring the formation of citrulline as described by Stalon et al. (1972). OTCase activity was measured at $55^{\circ} \mathrm{C}$ because of the thermal lability of CP. The reaction mixture contained, in a final volume of $2.0 \mathrm{ml}, 200 \mathrm{mM}$ Tris/ $\mathrm{HCl}$ buffer ( $\mathrm{pH} 7 \cdot 3$ at $\left.25^{\circ} \mathrm{C}\right), 2 \mathrm{mM}$ ornithine, $10 \mathrm{mM} \mathrm{CP}$ and extract. Unless otherwise specified, the incubation time was $5 \mathrm{~min}$. Formation of citrulline was linear during this time period.

ATCase (EC 2.1.3.2) activity was measured through the formation of carbamoyl aspartate. The reaction mixture contained in a total volume of $0.6 \mathrm{ml}, 0.17 \mathrm{M}$ Tris $/ \mathrm{HCl}$ buffer (pH 8.25), 0-5 units of enzyme, $5 \mathrm{mM} \mathrm{CP}$ and $10 \mathrm{mM}$ aspartate (pH 8.25). After $5 \mathrm{~min}$ incubation at $55^{\circ} \mathrm{C}$, the reaction was stopped by adding $0.4 \mathrm{ml} 5 \%$ trichloroacetic acid. Colorimetric measurements of carbamoyl aspartate formed were according to Prescott \& Jones (1969).

One enzyme unit is defined as the amount of enzyme that converts $1 \mu \mathrm{mol}$ substrate to product $\mathrm{h}^{-1}$. Protein concentrations were determined by the Lowry method.

Partial purification of CPSase. Frozen cells ( $40 \mathrm{~g}$ wet mass) were thawed in $20 \mathrm{ml} 50 \mathrm{mM}$ Tris/ $\mathrm{HCl}$ buffer $(\mathrm{pH} \mathrm{7.3)}$ and disrupted by sonication for $10 \mathrm{~min}$ in a Heat Systems ultrasonic oscillator ( $100 \mathrm{~W}, 20 \mathrm{kHz}$ ). Following sonication, the suspension was centrifuged at $20000 \mathrm{~g}$ for $30 \mathrm{~min}$. The supernatant was collected; the pellet, which consisted of sulfur and cell debris was discarded. Solid ammonium sulfate was added to the supernatant described above to $40 \%$ saturation and stirred for $1 \mathrm{~h}$. The solution was centrifuged at $20000 \mathrm{~g}$ for $30 \mathrm{~min}$. The supernatant was brought to $80 \%$ saturation, stirred for $1 \mathrm{~h}$, and then centrifuged at $20000 \mathrm{~g}$ for $30 \mathrm{~min}$. The pellet was suspended in $50 \mathrm{mM}$ Tris/ $\mathrm{HCl}$ buffer ( $\mathrm{pH} 7 \cdot 3$ ) and extensively dialysed against this buffer. The dialysed solution was applied to a DEAE Sepharose CL6B column $(1.6 \times 25 \mathrm{~cm})$ equilibrated with $50 \mathrm{mM}$ Tris/ $\mathrm{HCl}$ buffer $(\mathrm{pH} \mathrm{7 \cdot 3)}$. The CPSase activity was eluted with a linear gradient of $0-0.5 \mathrm{M} \mathrm{KCl}$, dissolved in $50 \mathrm{mM}$ Tris $/ \mathrm{HCl}$ buffer $(\mathrm{pH} \mathrm{7 \cdot 3}$ ). Active fractions were pooled and extensively dialysed against $50 \mathrm{mM}$ Tris $/ \mathrm{HCl}$ buffer (pH 7.3).

Determination of native molecular mass. The native molecular mass of CPSase was determined by measurement of its elution volume on a calibrated Sephadex G-200 SF column $(2.5 \times 35 \mathrm{~cm})$ which had been equilibrated with potassium phosphate buffer. A $1.2 \mathrm{ml}$ sample was applied, and $1.35 \mathrm{ml}$ fractions were collected at $5 \mathrm{ml} \mathrm{h}^{-1}$. Molecular mass standards used were catalase $\left(M_{r} 232000\right)$, aldolase (158000), albumin (67000), ovalbumin (43000), chymotrypsinogen A (25000) and ribonuclease A (13700).

\section{RESULTS}

\section{Thermal decomposition of CP in aqueous solution}

The kinetics of CP decomposition was investigated as a function of temperature. Aqueous solutions of

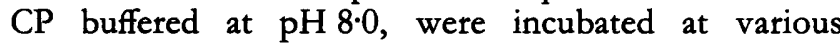
temperatures; after various time intervals, aliquots were withdrawn from these solutions and the residual $C P$ concentration determined enzymically. First-order rate constants $(k)$ were derived from the disappearance of CP; they were plotted as a function of temperature and the best fitting exponential curve was calculated (Fig. 2). Thermal decay was characterized by a $Q_{10}$ of 3 . There was no increase in decomposition rate when the ionic strength

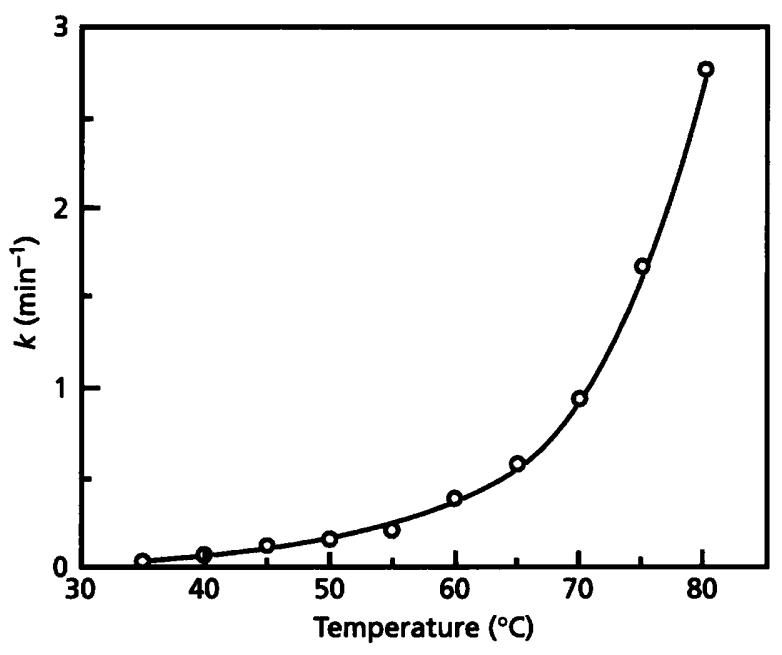

Fig. 2. Effect of temperature on the rate of $\mathrm{CP}$ decomposition. Solutions of $\mathrm{CP}(10 \mathrm{mM})$ buffered at $\mathrm{pH} 8.0$ were incubated at the temperatures indicated. At different time intervals, $0.1 \mathrm{ml}$ aliquots were withdrawn from each solution and immediately assayed for residual $\mathrm{CP}$ by converting it to citrulline in a reaction mixture containing $100 \mathrm{mM} \mathrm{Tris/HCl}$ buffer $(\mathrm{pH} \mathrm{8.0)}$ ), ornithine $20 \mathrm{mM}$ and 500 units $E$. coli OTCase $(1 \mathrm{~min}$ incubation at $30^{\circ} \mathrm{C}$. Data represent the means from three separate experiments. The values for replicate assays differed from the mean by $<10 \%$. The curve was obtained by exponential fitting of the data points. 
Table 1. Half-life times for the thermal decay of $\mathrm{CP}$ in aqueous solution

$t_{1 / 2}$ values for $\mathrm{CP}$ in aqueous solution, $0 \cdot 15 \mathrm{M}$ Tris $/ \mathrm{HCl}(\mathrm{pH} 8 \cdot 0)$, were calculated for temperatures between 0 and $100^{\circ} \mathrm{C}$ from the $k$ values extrapolated on the curve in Fig. $2\left(t_{1 / 2}=0.693 / k\right)$.

\begin{tabular}{|c|c|c|c|}
\hline \multirow{2}{*}{$\begin{array}{c}\text { Temperature } \\
\left({ }^{\circ} \mathrm{C}\right)\end{array}$} & \multicolumn{3}{|c|}{ Half-life time $\left(t_{1 / 2}\right)$} \\
\hline & $\mathbf{h}$ & $\min$ & $\mathbf{s}$ \\
\hline 0 & 20 & & \\
\hline 10 & 7 & & \\
\hline 20 & & 145 & \\
\hline 30 & & 50 & \\
\hline 35 & & 30 & \\
\hline 40 & & 21 & \\
\hline 50 & & 5 & \\
\hline 60 & & & 105 \\
\hline 70 & & & 52 \\
\hline 80 & & & 15 \\
\hline 90 & & & 5 \\
\hline \pm 100 & & & $<2$ \\
\hline
\end{tabular}

of the solution was increased (presence of $\mathrm{KCl}$ at concentrations up to $500 \mathrm{mM}$ ). There was no noticeable difference between $k$ values obtained at $\mathrm{pH} 7 \cdot 5$ or $\mathrm{pH} 9 \cdot 0$ in Tris/ $\mathrm{HCl}$ buffer (results not shown). Table 1 lists a series of half-life times for $\mathrm{CP}$ at $\mathrm{pH} 8 \cdot 0$, obtained by extrapolation of the curve of Fig. 2. At the optimal growth temperature of $P$. furiosus $\left(100-102{ }^{\circ} \mathrm{C}\right.$; Fiala \& Stetter, 1986), the half-life of CP was less than $2 \mathrm{~s}$.

\section{Identification of an ammonia-dependent CPSase activity in cell-free extracts of $P$. furiosus}

The failure to detect CPSase activity in cell-free extracts of the archaea $P$. furiosus and Sulfolobus solfataricus, where both ATCase and OTCase are present, has been reported previously (Van de Casteele et al., 1990). Since the latter publication, a CPSase activity using both glutamine and ammonia as a nitrogen donor has, however, been detected in S. solfataricus extracts (Piérard et al., 1992). In this work, we reinvestigated the synthesis of CP in $P$. furiosus and were able to identify an ammonia-dependent CPSase activity during incubation of extracts of this organism at $60^{\circ} \mathrm{C}$; no activity could be detected when $\mathrm{NH}_{4} \mathrm{Cl}$ was replaced by glutamine. This lack of activity was observed at both 60 and $90^{\circ} \mathrm{C}$ (Table 2). As the synthesis of $\mathrm{CP}$ from ATP, bicarbonate and ammonia could at first sight appear to result from the reverse action of carbamate kinase (an enzyme involved in the deiminase pathway for arginine degradation, see Cunin et al., 1986 and Fig. 1), we assayed crude extracts of $P$. furiosus for its presence, using the technique described in Methods. The failure to detect

\section{Table 2. Substrate specificity of $P$. furiosus CPSase in crude extract or in a partially purified preparation}

Activities are the means of at least two independent experiments. The values for replicate assays differed from the mean by $<10 \%$ when measured at $60^{\circ} \mathrm{C}$ and $<20 \%$ when measured at $90^{\circ} \mathrm{C}$. ND, not determined.

\begin{tabular}{|c|c|c|c|c|}
\hline \multirow[t]{3}{*}{ Substrate (concentration, $\mathbf{m M}$ ) } & \multirow{3}{*}{$\begin{array}{c}\text { Effector } \\
\text { (concentration, } \mathrm{mM} \text { ) }\end{array}$} & \multicolumn{3}{|c|}{ Specific activity [units (mg protein $)^{-1}$ ] } \\
\hline & & \multicolumn{2}{|c|}{ Crude extract } & \multirow{2}{*}{$\begin{array}{c}\text { Partially } \\
\text { purified } \\
\text { enzyme } \\
\left(60^{\circ} \mathrm{C}\right)\end{array}$} \\
\hline & & $\left(60^{\circ} \mathrm{C}\right)$ & $\left(90^{\circ} \mathrm{C}\right)$ & \\
\hline $\mathrm{NH}_{4} \mathrm{Cl}(100) ; \mathrm{NaHCO}_{3}(20) ; \operatorname{MgATP}(3)$ & None & $3 \cdot 4$ & $15 \cdot 4$ & $21 \cdot 0$ \\
\hline Glutamine (50); $\mathrm{NaHCO}_{3}(20) ; \operatorname{MgATP}(3)$ & None & $<0.001$ & $<0.001$ & $<0.001$ \\
\hline $\mathrm{NH}_{4} \mathrm{Cl}(100) ; \mathrm{NaHCO}_{3}(20)$ & None & $<0.001$ & ND & ND \\
\hline $\mathrm{NH}_{4} \mathrm{Cl}(100) ; \mathrm{NaHCO}_{3}(20) ; \operatorname{MgATP}(3)$ & $N$-Acetylglutamate (20) & $3 \cdot 0$ & $14 \cdot 9$ & $21 \cdot 6$ \\
\hline Glutamine (50); $\mathrm{NaHCO}_{3}(20) ; \operatorname{MgATP}(3)$ & $N$-Acetylglutamate (20) & $<0.001$ & ND & ND \\
\hline $\mathrm{NH}_{4} \mathrm{Cl}(100) ; \mathrm{NaHCO}_{3}(20) ; \mathrm{MgATP}(3)$ & UMP (10) & $3 \cdot 2$ & $14 \cdot 7$ & $20 \cdot 1$ \\
\hline Glutamine (50); $\mathrm{NaHCO}_{3}(20) ; \operatorname{MgATP}(3)$ & UMP (10) & $<0.001$ & ND & ND \\
\hline $\mathrm{NH}_{4} \mathrm{Cl}(100) ; \mathrm{NaHCO}_{3}(20) ; \mathrm{MgATP}(3)$ & $\operatorname{IMP}(10)$ & $3 \cdot 1$ & $15 \cdot 3$ & $19 \cdot 8$ \\
\hline Glutamine (50); $\mathrm{NaHCO}_{3}(20) ; \operatorname{MgATP}(3)$ & $\operatorname{IMP}(10)$ & $<0 \cdot 001$ & ND & ND \\
\hline
\end{tabular}

Table 3. Partial purification of $P$. furiosus CPSase

\begin{tabular}{|lcccc|}
\hline Purification step & $\begin{array}{c}\text { Total protein } \\
\text { (mg) }\end{array}$ & $\begin{array}{c}\text { Total activity } \\
\text { (units) }\end{array}$ & $\begin{array}{c}\text { Specific activity } \\
\text { [units (mg protein) }\end{array}$ & $\begin{array}{c}\text { Yield } \\
\text { (\%) }\end{array}$ \\
\hline Crude extract & 3510 & 12300 & $3 \cdot 5$ & 100 \\
$\left.\mathrm{NH}_{4}\right)_{\mathbf{2}} \mathrm{SO}_{\mathbf{4}}$ fractionation & 2400 & 10660 & $4 \cdot 4$ & 87 \\
$\mathrm{DEAE} \mathrm{Sepharose} \mathrm{chromatography}^{\text {[moly }}$ & 380 & 7990 & $21 \cdot 0$ & 65 \\
\hline
\end{tabular}


any $\mathrm{CO}_{2}$ evolution upon incubation of crude cell-free extracts with $\mathrm{CP}$ and MgADP indicates that the ammoniadependent CP synthesis is not due to carbamate kinase catalysing the reversible phosphorylation of carbamate by ATP. Moreover, no arginine deiminase activity could be detected in crude cell-free extracts (unpublished results). The CP-catalysing activity of $P$. furiosus extracts can thus be regarded as a CPSase. Partial purification and further characterization of this ammonia-dependent CPSase activity is described below.

\section{Properties of CPSase from P. furiosus}

Partial purification and molecular mass determination. Table 3 summarizes the partial purification of CPSase from $40 \mathrm{~g}$ (wet mass) of frozen $P$. furiosus cells. The preparation obtained after DEAE Sepharose chromatography yielded several bands during gel electrophoresis, but was free of ATCase and OTCase activities. It was used further for kinetic and thermal stability studies.

When this enzyme preparation was submitted to gel filtration on Sephadex G200, the CPSase activity eluted as a single peak at a position corresponding to a $M_{\mathrm{r}}$ of about 70000 . Similar results were obtained when a crude extract was submitted to gel filtration on Sephadex G200 (not shown).

Thermal stability. P. furiosus CPSase exhibited marked thermal stability. A partially purified preparation obtained after DEAE Sepharose chromatography (Table 3) was incubated for various times $(0-120 \mathrm{~min})$ at $100^{\circ} \mathrm{C}$ in $20 \mathrm{mM}$ potassium phosphate buffer $(\mathrm{pH} 7 \cdot 5)$. The protein concentration was $10 \mathrm{mg} \mathrm{ml}^{-1}$. These incubations were performed in sealed tubes. The residual CPSase activity of each sample was determined by the standard assay (see Methods). A half-life of $45 \mathrm{~min}$ was determined by plotting the logarithm of the residual activity versus the time of preincubation at $100^{\circ} \mathrm{C}$ (not shown).

Substrate specificity and kinetic parameters. The most striking property of $P$. furiosus CPSase is its absence of reactivity towards glutamine. In partially purified preparations, as in crude extracts, only ammonia was used as the nitrogen donor in the reaction (Table 2). The values of the apparent $K_{\mathrm{m}}$ for bicarbonate and $\mathrm{NH}_{4} \mathrm{Cl}$, determined using the Lineweaver-Burk and Hanes-Woolfs plots, were $3.8 \pm 0.2 \mathrm{mM}$ and $0.6 \pm 0.3 \mathrm{mM}$, respectively. The effect of MgATP concentration (at equimolar concentrations of ATP and magnesium ions) on the initial rate of the reaction was described by a sigmoid curve with half-maximal activity being observed at a concentration of $0.5 \mathrm{mM}$. Neither UMP, nor IMP or $N$-acetylglutamate had any effect on the activity of the enzyme at 60 or $90^{\circ} \mathrm{C}$. No evidence was obtained for an effect of triphosphonucleotides.

\section{Competition between CP synthesized by CPSase and exogenous $\mathrm{CP}$ in the production of citrulline}

The question of $\mathrm{CP}$ channelling was addressed by isotopic competition: a crude extract of $P$. furiosus $(40 \mathrm{mg}$ protein $\mathrm{ml}^{-1}$ ) was incubated either at $37^{\circ} \mathrm{C}$ or at $55^{\circ} \mathrm{C}$ with

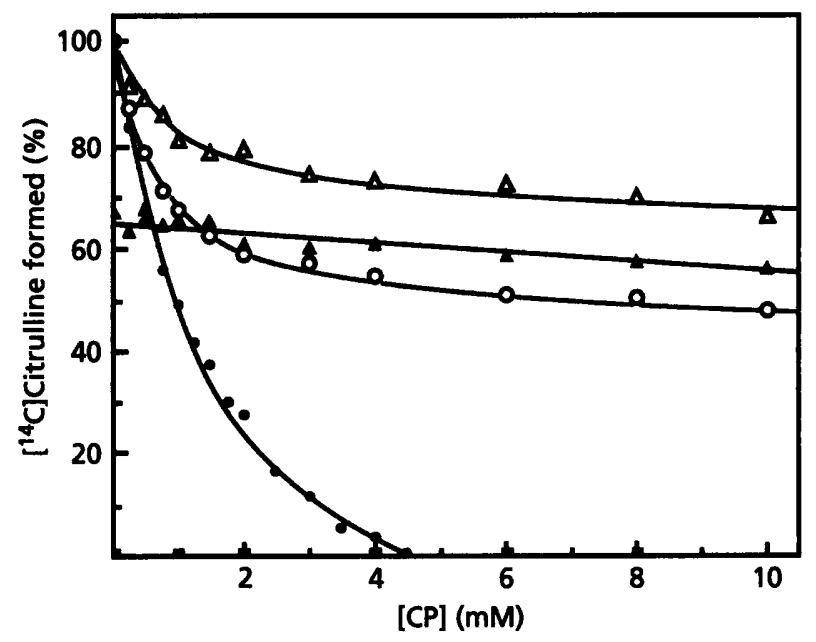

Fig. 3. Influence of exogenous unlabelled CP on the utilization of labelled CP synthesized by CPSase for citrulline production. Cell-free extracts ( $40 \mathrm{mg}$ protein $\mathrm{I}^{-1}$ ) were incubated in the presence of increasing amounts of unlabelled $\mathrm{CP}$; the reaction was started by adding the CPSase substrates (at saturating level) and $\left[{ }^{14} \mathrm{C}\right]$ citrulline formed was determined after incubation as described in Methods. $\left[{ }^{14} \mathrm{C}\right]$ Citrulline formed is expressed as a percentage of the value obtained in the absence of unlabelled exogenous CP and PALO. $\triangle, P$. furiosus extract incubated at $55^{\circ} \mathrm{C}$ for $5 \mathrm{~min}$; $O, P$. furiosus extract incubated at $37^{\circ} \mathrm{C}$ for $15 \mathrm{~min} ; \triangle, P$. furiosus extract incubated at $55^{\circ} \mathrm{C}$ for $5 \mathrm{~min}$ in the presence of $1 \mathrm{mM}$ PALO; $O, E$. coli extract incubated at $37^{\circ} \mathrm{C}$ for $15 \mathrm{~min} ; \mathrm{C}, E$. coli extract incubated at $37^{\circ} \mathrm{C}$ for $15 \mathrm{~min}$ in the presence of $1 \mathrm{mM}$ PALO. Each experiment was repeated at least two times without significant differences; results shown are the means of two replicates.

radioactive bicarbonate in the presence of increasing concentrations of unlabelled $\mathrm{CP}$ and the amount of radioactive citrulline formed was then determined as described in Methods. For comparison, an extract of $E$. coli $\mathrm{K} 12$ was treated in the same way (at $37^{\circ} \mathrm{C}$ only). The results are shown in Fig. 3. After an initial steep decline, indicating the presence of some free OTCase in the extract, the curve almost levelled off; very little competition apparently occurred when the $\mathrm{CP}$ concentration was increased further, suggesting the existence of a CPSase/OTCase complex channelling $\mathrm{CP}$ rather efficiently. The amount of free OTCase seemed to be higher at $37^{\circ} \mathrm{C}$ than at $55^{\circ} \mathrm{C}$, indicating that a higher percentage of this channelling complex may form at higher temperature. Under the same conditions, competition occurred in the $E$. coli extract at the lowest concentrations tested. We also tested the effect of the bisubstrate analogue $\delta$ - $N$-phosphonoacetyl-L-ornithine (PALO) in the experiment described in Fig. 3. As expected from the fact that this substance inhibits purified $P$. furiosus OTCase $(80 \%$ inhibition at $1 \mu \mathrm{M}$ concentration; C. Legrain, unpublished results), addition of PALO to the system provoked $30-35 \%$ inhibition of the amount of citrulline formed in the absence of competing $\mathrm{CP}$, that is by the free OTCase present in the extract. However, at increasing concentrations of CP, PALO displayed only a modest effect (about 15\% inhibition, see Fig. 3). This 
suggests reduced accessibility of OTCase to PALO in the channelling complex. In contrast, a $100 \%$ inhibition of the E. coli system by PALO was observed, indicating that such channelling does not occur in this system under the conditions used.

\section{DISCUSSION}

Our studies indicate that $P$. furiosus synthesizes $\mathrm{CP}$ by a mechanism which appears to be unique among the micro-organisms investigated to date, in that ammonia and not glutamine is the nitrogen donor in the reaction. The enzyme thus behaves as the large subunit of class II CPSases. However, the disparity in $M_{\mathrm{r}}$ (120000 for the large subunit and 70000 for the native $P$. furiosus CPSase) prevents further comparisons in the absence of primary structure data. The $P$. furiosus CPSase gene will have to be cloned and sequenced before proposing possible homologies and structure-function relationships. The novel character of $P$. furiosus CPSase makes it particularly relevant from the point of view of phylogeny, when considering current hypotheses on the possible primeval character of hyperthermophiles.

Our data concerning the kinetics of $\mathrm{CP}$ decomposition establish that this intermediate is indeed extremely labile at high temperatures and would therefore appear to require metabolic protection in vivo. Experiments described in this paper suggest channelling of CP towards citrulline, a mechanism which could protect $\mathrm{CP}$ against thermal decomposition. Competition experiments between labelled CP produced by CPSase and unlabelled CP added to the reaction mixture showed a marked preference of OTCase for the utilization of CP synthesized by CPSase. Since the purification schemes used clearly show that CPSase and the carbamoyltransferases of $P$. furiosus are not integral parts of the same protein, such findings suggest that CPSase and OTCase associate to form a multienzyme complex able to channel this labile intermediate. The fact that the bisubstrate analogue PALO only slightly inhibits the formation of citrulline from bicarbonate, ammonia, ATP and ornithine under the conditions where it inhibits free OTCase, is further evidence for the existence of this complex.

In Saccharomyces cerevisiae, channelling of $\mathrm{CP}$ has also been observed (Belkaild et al., 1988) but in this case it is known that CPSase and ATCase activities are carried out by the same polypeptide chain. CP appears to be channelled between CPSase and OTCase in rat liver mitochondria (Cohen et al., 1992). To our knowledge the results presented here are the first indications of CP channelling in prokaryotes. The question whether CP channelling is a prerequisite for arginine and pyrimidine metabolism at high temperature, can be addressed by studying the phenomenon in a variety of phylogenetically unrelated hyperthermophiles.

The question of the non-utilization of glutamine as amino group donor by Pyrococcus CPSase is interesting to consider in relation to the hyperthermophilic character of its host. The $\gamma$-amido group of glutamine is unstable in hot aqueous solutions and this instability is considerably enhanced in the presence of bicarbonate and phosphate ions (Gilbert et al., 1949), respectively substrate and product of the reaction catalysed by CPSase. As the temperature optimum of $P$. furiosus is between 100 and $102^{\circ} \mathrm{C}$, one therefore wonders whether glutamine would have been an appropriate source of nitrogen for CP synthesis in this and similar organisms. We therefore suggest, as a working hypothesis, that hyperthermophily may be associated with the preferential use of ammonia as nitrogen donor for CP synthesis. Similarly, it may be that other reactions using glutamine as amino group donor in mesophiles will be found to use ammonia in hyperthermophiles. Clearly, several key reactions of biosynthetic metabolism are worth examining in these organisms.

\section{ACKNOWLEDGEMENTS}

We thank D. Gigot for the synthesis of $\delta$ - $N$-phosphonoacetylL-ornithine. This work was supported by the Belgian Foundation for Fundamental and Joint Research (FRFC-FKFO), by a Concerted Action between the Vrije Universiteit Brussel and the Vlaamse Gemeenschap, by the Vlaams Actieprogramma Biotechnologie and by the European Community Programme Biotechnology.

\section{REFERENCES}

Allen, C. M. \& Jones, M. E. (1964). Decomposition of carbamoylphosphate in aqueous solution. Biochemistry 3, 1238-1247.

Anderson, P. M. (1980). Glutamine- and $N$-acetylglutamate-dependent carbamyl phosphate synthetase in elasmobranchs. Science 208, 291-293.

Anderson, P. M. (1981). Purification and properties of the glutamine- and $\mathrm{N}$-acetyl-L-glutamate-dependent carbamylphosphate synthetase from liver of Squalus acantbias. J Biol Cbem 256, 12228-12238.

Belkaîd, M., Penverne, B. \& Hervé, G. (1988). In situ behavior of pyrimidine pathway enzymes in Saccharomyces cerevisiae. 3. Catalytic and regulatory properties of carbamoylphosphate synthetase: channeling of carbamylphosphate to aspartate transcarbamylase. Arch Biocbem Biophys 262, 171-180.

Casey, C. A. \& Anderson, P. M. (1983). Glutamine- and N-acetyl-Lglutamate-dependent carbamyl phosphate synthetase from Micropterus salmoides. J Biol Chem 258, 8723-8732.

Cohen, N. S., Cheung, C. W., Sijuwade, E. \& Raijman, L. (1992). Kinetic properties of carbamoyl-phosphate synthetase (ammonia) and ornithine carbamoyltransferase in permeabilized mitochondria. Biochem J 282, 173-180.

Coleman, P. F., Suttle, D. P. \& Stark, G. R. (1977). Purification from hamster cells of the multifunctional protein that initiates de novo synthesis of pyrimidine nucleotides. J Biol Chem 252, 6379-6385.

Cunin, R., Glansdorff, N., Piérard, A. \& Stalon, V. (1986). Biosynthesis and metabolism of arginine in bacteria. Microbiol Rev 50, 314-352.

Davis, R. H. (1986). Compartmental and regulatory mechanisms in the arginine pathway of Neurospora crassa and Saccharomyces cerevisiae. Microbiol Rev 50, 280-313.

Elliot, K. R. F. \& Tipton, K. F. (1973). Purification and characterization of carbamoylphosphate synthetase from beef liver. FEBS Lett 37, 79-81. 
Fiala, G. \& Stetter, K. O. (1986). Pyrococcus furiosus sp. nov. represents a novel genus of marine heterotrophic archaebacteria growing optimally at $100^{\circ} \mathrm{C}$. Arch Microbiol 145, 56-61.

Gilbert, J. B., Price, V. E. \& Greenstein, J. P. (1949). Effect of anions on the non-enzymatic desamidation of glutamine. J Biol Chem 180 , 209-218.

Hager, S. E. \& Jones, M. E. (1967). Initial steps in pyrimidine synthesis in Ehrlich ascites carcinoma in vitro. II. The synthesis of carbamyl phosphate by a soluble, glutamine-dependent carbamyl phosphate synthetase. J Biol Chem 242, 5667-5673.

Jones, M. E. (1980). Pyrimidine nucleotide biosynthesis in animals: genes, enzymes, and regulation of UMP biosynthesis. Annu Rev Biochem 42, 253-279.

Legrain, C. \& Stalon, V. (1976). Ornithine carbamoyltransferase from Escherichia coli W. Purification, structure and steady-state kinetic analysis. Eur J Biochem 63, 289-301.

Lusty, C. J. (1978). Carbamoylphosphate synthetase I of rat liver mitochondria. Eur J Biochem 85, 373-383.

Mathews, C. K. (1993). The cell-bag of enzymes or network of channels? J Bacteriol 175, 6377-6381.

Meister, A. (1989). Mechanism and regulation of the glutaminedependent carbamoylphosphate synthetase of Escherichia coli. Adv Enzymol 55, 315-374.

Mori, M. \& Cohen, P. P. (1978). Preparation of crystalline carbamyl phosphate synthetase I from frog liver. J Biol Chem 253, 8337-8339.

Ovádi, J. (1991). Physiological significance of metabolic channeling. $J$ Theor Biol 152, 1-22.
Piérard, A., Glansdorff, N. \& Yasphe, J. (1972). Mutations affecting uridine monophosphate pyrophosphorylase or the $\arg \mathrm{R}$ gene in Eschericbia coli. Effects on carbamoylphosphate and pyrimidine biosynthesis and uracil uptake. Mol \& Gen Genet 118, 235-245.

Piérard, A., Legrain, C., Demarez, M., Roovers, M., Van de Casteele, M. \& Glansdorff, N. (1992). Enzymes of carbamoylphosphate metabolism in hyperthermophilic archaebacteria. In Thermophiles: Science and Technology, Abstract Book, Reykjavik, Iceland.

Prescott, L. M. \& Jones, M. E. (1969). Modified methods for the determination of carbamylaspartate. Anal Biochem 32, 408-419.

Srere, P. A. (1987). Complexes of sequential metabolic enzymes. $J$ Theor Biol 152, 21-56.

Stalon, V., Ramos, F., Piérard, A. \& Wiame, J. M. (1972). Regulation of the catabolic ornithine carbamoyltransferase of Pseudomonas fluorescens. A comparison with the anabolic transferase and with mutationally modified catabolic transferase. Eur $J$ Biocbem 29, 25-35.

Van de Casteele, M., Demarez, M., Legrain, C., Glansdorff, N. \& Piérard, A. (1990). Pathways of arginine biosynthesis in extreme thermophilic archaeo- and eubacteria. J Gen Microbiol 136, 1177-1183.

Williams, L. G., Bernhardt, S. \& Davis, R. H. (1970). Copurification of pyrimidine-specific carbamyl phosphate synthetase and aspartate transcarbamylase of Neurospora crassa. Biochemistry 9, 4329-4335.

Received 31 October 1994, revised 30 January 1995, accepted 14 February 1995. 